\title{
Sensitivity and Specificity of OMP Acinetobacter Baumannii Antigen Dot Blot to Detect Secretory-IgA in Urine of Patients with Acinetobacter BaumanniiInfection
}

\author{
Salah Benaessa Mohmed Salah ${ }^{1}$, KusworiniHandono ${ }^{2}$, SumarnoR.Prawiro ${ }^{3}$ \\ ${ }^{I}$ (Magister of Biomedical Sciences, Faculty of Medicine / Brawijaya University, Malang, Indonesia) \\ ${ }^{2}$ (Department of Clinical Pathology, Faculty of Medicine/ Brawijaya University, Malang, Indonesia) \\ ${ }^{3}$ (Department of Microbiology, Faculty of Medicinel Brawijaya University, Malang, Indonesia)
}

\begin{abstract}
Urinary tract infections (UTI) represent one of the nosocomial infections in hospitals. One of the most common agents of nosocomial urinary tract infections is an A.baumannii bacteria. In addition to other infections for example, cystitis, acute and chronicpyelonephritis, kidneybladder stone, bacteremia and sepsis, etc. So far, thisisused to identifybacteriastaining and culture methods, whichrequire a long time. The aimed of this studywas to detectbacteria in urinary tract infections (UTI) caused by A.baumanniiusing the principles of serologicalreactions Dot blot method. The result by doing to see the humoral immune responsesecretory-IgA (s-IgA) as antibodyagainstOMPspecificas antigenA.baumanniibacteria.Thisstudy design wasdividedintotwo stages. First stage is an explorativeexperimental to obtain an antigendeliveredform OMP of A.baumannii, followed by the second stage of an experimentallaboratory for the identification of an immune response of $s$ IgAfrom urine patients suspected of sufferingfrom a bacterial UTI. In addition, ithelps to make a clinicaldiagnosis of UTI cases using dot blot. Urine sampleswithresultsgroupedinto positive and negativebolt bot urine cultures as comparedwith the gold standard.The results of the study also show that the molecular weight of OMP A.baumannii $57.2 \mathrm{kDa}$ responded to s-IgA. An examination was made of the humoral immune response to an antigens-IgA $57.2 \mathrm{kDaA}$.baumannii. The Dot blot examination and culture examination were based on the gold standard in 110 urine samples obtained at 42,44 with mean cut-off value of sensitivity 71.43 $\%$, specificity 95. 15.\%, Positive predictive 50, $00 \%$ and negative predictive 98, $00 \%$.Clinical application still needs to be done as well as more in-depth research related to the development of this method.
\end{abstract}

Keywords: Urinary tract infection, A.baumannii, OMP, sIgA, dot blot

\section{Introduction}

Urinary tract infection(UTI) is one of the most common bacterial infections encountered by clinicians in developing countries [1]. Over $53 \%$ of all women and $14 \%$ of men experience at least one UTI in their lives [2]. One of the most common agents of nosocomial urinary tract infections is Acinetobacter baumannii(A. baumanii)bacteria.

Acinetobacterbaumannii an opportunistic pathogen or nosocomial pathogens, can be found naturally in the environment, soil, water and dirt [3] or even in the mucosa farings and healthy skin [4]. Human infection usually occurs in patients with immune compromised. Theclinical form of the disease is nosocomialinfections, especially in patients with pneumonia [5], infection of the eye, infections in burns or surgical wounds, skin infections, urinary tract infections, bacteremia and septicemia [6].

Many bacterial factors are known to be involved in the pathogenic mechanism of Acinetobacter.sppinfection. Recent researches on the pathogenicity of Acinetobacterspphave focused on 5 major factors, namely bacterial capsule, fimbriae (pili), serum resistance, LPS, and siderophores [7]

The three components of the outermembrane wall of gram negative bacteria thought to be involved in the development of immunity are LPS, membrane proteoglycans and outer membrane proteins (OMP). OMP or Afimbrialadhesin is a surface protein, attached to a host more powerful than pili [8].

One of the firstline defense mechanisms of the urinary tract is secretory-IgA $(\operatorname{sg} A)$, which has been selected to protect mucosal surfaces. SIgA has unique properties (high valence for antigen binding and relatively resistant to proteolysis commensal microflora) to fulfill its role in mucosal immunity [9].

To identify of A.baumannii, the methods that can be used is culture, which require quite a long time. This study seeks to determine the s-IgA responses against specific antigens OMP A.baumanniiin UTI patients with Dot blot method. 


\section{Culture A.baumannii}

\section{Material and Methods}

The bacteria used in this research was Abaumanni.Itwasderived from the Clinical MicrobiologyLaboratory in general hospital at Malang, Indonesia. The TCG medium was used to enrich the growth of bacterial pili. TCG medium contained $0.02 \%$ thioproline, $0.3 \%$ NaHCO 3, $0.1 \%$ mono sodium 1-glutamate, $1 \%$ bacto-tryptone, $0.2 \%$ yeast extract, $0.5 \% \mathrm{NaCl}, 2 \%$ bacto $\beta$-agar and $1 \mathrm{mM}$ amino-ethyl ether- $\mathrm{N}, \mathrm{N}, \mathrm{N}$, "n",-tetra acetic acid (EGTA)[10]. The 250-ml volume bottles were filled with $50 \mathrm{ml}$ TCG media. After TCGonthemediumsolidified the bottleis pouredwithBrain Heart Infussion Broth (BHI) mediumthat hasgrownbyA.baumannii. Incubation was performed at $37^{\circ} \mathrm{C}$ for $2 \times 24$ hours.

\section{Isolation of Bacteria A.baumannii free pili and flagella}

PurificationOMPdoneafterremovingthebacterialflagellaandpili. The methode reffered to our recent study by using pili bacteria cutter [11].

The collection of bacteria from 20 roux bottles media were re-suspended using tri chlor acetic acid until the concentration reached $3 \%$. The suspension was shaken thoroughly for 30 seconds and stood at room temperature for 1 hour. The pellet was collected by centrifugation of suspense with a speed of $6.000 \mathrm{rpm}$, for 30 minutes and temperature of $4^{\circ} \mathrm{C}$. Three gr of the pellet were re-suspended with $6 \mathrm{ml}$ of PBS pH 7.4. The suspended bacteria were placed into the tube of the pili bacteria cutter.

After that, the pili bacteria cutter was adjusted for the first cutting at a speed of 12, $000 \mathrm{rpm}$, for 30 seconds at a temperature of $4^{\circ} \mathrm{C}$. The supernatant contained rich piliand flagella protein so the bacteria was separated to get the pellet. The supernatant was discarded and the pellet was stored at $4^{\circ} \mathrm{C}$.

\section{Electron scanning microscope instruction method}

The instruction method was done as our previous study[12].The bacterial pellet was isolated from the bacteria culture grown in TCG media using centrifugation. The sample dilution had a 1:100 ratio. Preparations were made on the cover glass and then fixed by using methanol. Furthermore, the sample was put in the instrument sputter coater for coating with gold-palladium coating to turn it into a seemingly purple color. Samples were removed from the engine sputter coater, and then inserted into the SEM.

\section{Acinetobacterbaumannii OMP protein isolation}

Isolation was performed according Sumarno, et al (1988) [13]. With slight a modification from Evan's method. Modifications made in the free pili and flagella precipitated bacteria at the last round cutting and did not do column chromatography separation. Pellets were suspended with PBS pH 7.4 until the volume reaches 5 times, then added SDS until concentration reaches $0.05 \%$. Then performed using a vortex homogenization with full speed for 1 minute. After that centrifugation done with speed $12000 \mathrm{rpm}$. At $4^{0} \mathrm{C}$ for 15 minutes. The supernatant was collected and stored at $4^{0} \mathrm{C}$.

\section{Sodium Dodecyl Sulfate Polyacrylamid Gel Electrophoresis (SDS-PAGE)}

Monitoring molecular weight (MW) protein is done according to SDS -PAGE method of Laemmli [14]. Protein samples were heated at $100^{\circ} \mathrm{C}$ for 5 minutes in a buffer solution containing $5 \mathrm{mMTrisHCl} \mathrm{pH} 6.8,5 \% 2$ - mercapto ethanol, $2.5 \% \mathrm{w} / \mathrm{v}$ sodium dodecyl sulfate, $10 \% \mathrm{v} / \mathrm{v}$ glycerol using color tracker Bromophenol blue. A $12.5 \%$ mini slab gel with a $4 \%$ gel tracking was selected. The electrical voltage used was $120 \mathrm{mV}$. The color of the material was Coomassie brilliant blue. A fermentas marker standard was used.

\section{Purification protein from OMP A.baumannii}

Instructions for such a research conducted by Ehara were applied with some modifications [15]. The results of the OMP collection were obtained using SDS-PAGE.Gel was cut straight to the desired molecular weight and band pieces were collected and put into a dialysis membrane tube contained electrophoresis running buffer fluid. Electro-elution was performed by using a horizontal electrophoresis apparatus at $120 \mathrm{mV}$ voltage for 60 minutes. The dialysis process used $\mathrm{dH} 2 \mathrm{O}$ during 24 hours and continued at night that utilizes $\mathrm{PBS} \mathrm{pH} 7.4$ at the rate of $2 \times 24$. The solution rich purified protein in membrane tube was collected after pieces of band gel was decarded to concentred protein in the solution obtained by using precipitation in cold absolute ethanol.

\section{Hemagglutination test method}

Hemagglutination assay was done according to the instructions of Hanne and Finkelstein's [16]. Sample dilutions were made on $1 / 2$ concentration in microplate $\mathrm{V}$ where each well volume was $50 \mu \mathrm{l}$. In every well, the same volume of $50 \mathrm{ul}$ of red blood suspension of mice with a concentration of $0.5 \%$ was added. Then it was shaken using a rotator plate for 1 minute. Subsequently it was placed at room temperature for 1 hour. The titer was determined by observing the agglutination of red blood at the lowest dilution. 


\section{Western Blotting method}

The Western Blotting method refers to a technical protocol by Biorad [17]. The SDS-PAGE gel results containing protein bands were transferred onto nitrocellulose (NC) membrane using a semi-dry blotter (Biorad). After that the NC membrane containing protein SDS-PAGE gel was incubateed overnight and washed with TBE plus $0.05 \%$ tween 20 concentrations twice. Furthermore, the primary antibody of human s-IgA concentration of $1 / 1000$ in TBE pH 7.4 containing $1 \%$ solution of BSA concentration was given to the NC. It was washed again using the same solution and then the anti-human secondary antibody IgA concentration of 1/1000 in TBE $\mathrm{pH}$ 7.4 and BSA with concentration of $1 \%$ were added. Subsequently, it was washed twice for 5 minutes using TBE $\mathrm{pH} 7.4$ with tween 20 concentration of $0.05 \%$. Cip $\beta$ as the material used color tablet.

\section{Dot Blot method}

Dot Blot is used to detect reactions between antigens and antibodies. NC was cut by $7.5 \times 11 \mathrm{~cm}$ and was inserted between two pieces of metal blotter apparatus. Then it was mounted on the dot blot, incubated overnight at a temperature of $40^{\circ} \mathrm{C}$ or antigen in degas until it was completely absorbed into the membrane NC. Further TBS blocking was carried out using a blocking buffer (containing 50 mMTris Base, $0.2 \mathrm{M} \mathrm{NaCl}, 5 \%$ skim milk, pH 7.4). The next stage in the membrane, $50 \mathrm{~mL}$ of primary antibody was spilled, incubated for $2 \mathrm{~h}$ at room temperature and placed on a shaker. The solution was removed, and then washed 3 times with TBS$0.05 \%$ Tween-20.The secondary antibody with 1:15000 dilution was added. Again it was washed 3 times with TBS- $0.05 \%$ Tween-20 and chromogenic substrate (BCIP-NBT) was added[18].

To get the standard in assessing the results of each dot in this study used the program Corel Photo Paint 12 to obtain accurate data on the thickness of the black spots on the nitrocellulose membrane. The program is complete with the computer data such as mean, standard deviation, median and pixel. Subsequently, a table that contains the relationship between the four parameters of each urine sample is drawn up. These four parameters are used. Of one of the parameters, the mean of the parameter is use to calculate the sensitivity, positive predictive value and negative (Mc Nemar) to determine the sensitivity and specificity. This is done by replacing the cut-off part of each for each experiment. Also tested are the sensitivity and specificity of the dot blot method.

\section{Morphologyof A.baumanniibacteria}

\section{Result}

Before and after the cutting of pili of A.baumannii. The whole cell morphologyof A.baumanniiwas observed using a scanning electron microscope.

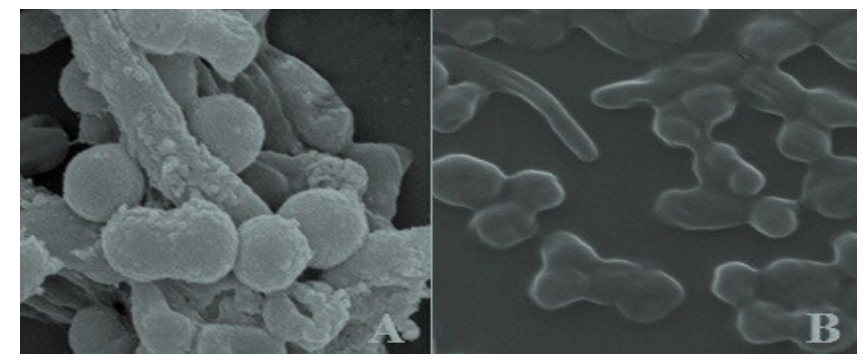

Figure1. Result of morphologyof A.baumanniibacteria using ascanning electronmicroscope/SEM (50.000x magnification).

\section{Description:}

A.Bacterial cellsA.baumanniibeforepilicutting

B.Bacterial cellsA.baumanniiafterpilicutting. 


\section{AcinetobacterBaumanniiOMP protein profiles using SDS-PAGE}

This phase of the study aimed to determine the profile of protein bands that appeared on the OMP. Protein bands that appeared calculated molecular weight (MW) using calculation method compared with the low protein marker.

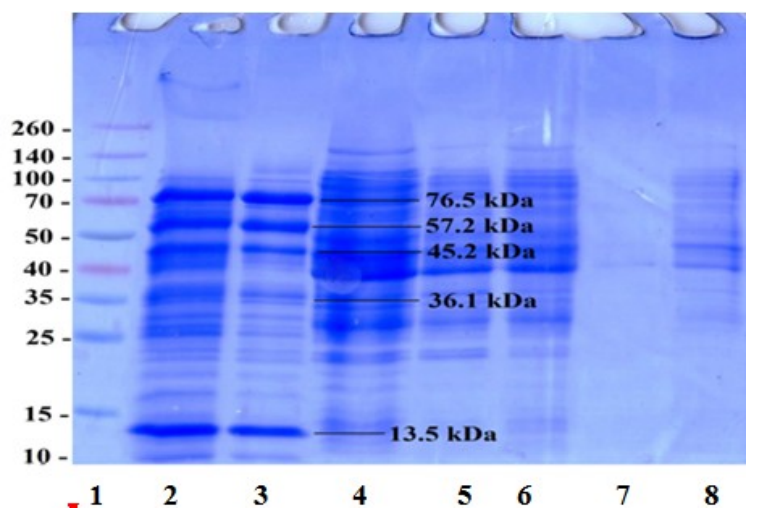

Figure 2. Result of A.baumanniiOMP protein profile using SDS-PAGE Description:

1. Marker (protein tracer)

2. and 3. OMP $(0.5,0.05)$ A.baumannii

4. 5. 6. and 7. Piece of Pili (P1, P2, P3, and P4)A.baumannii

8.PelletA.baumannii

By doing electrophoresis using SDS PAGE, the profile of protein bands can be seen appearing on the OMP protein. The MW of OMP protein to be confirmed are 13.5 kDa, 36.1 kDa, 45.2 kDa, 57.2 kDa and 76.5 $\mathrm{kDa}$. Then the OMP with the molecular weight are cut and electro-elution and dialysis are performed to purify the protein hemagglutinin of the non-ionic detergent remnants. The next dialysis results of agglutination dialysis test are then performed to determine which one is the highest titer of OMP $\mathrm{kDa}$ protein as the protein hemagglutinin.

\section{Hemagglutination test (HA test) of OMP $13.5 \mathrm{kDa}, 36.1 \mathrm{kDa}, 45.2 \mathrm{kDa}, 57.2 \mathrm{kDa}$ and 76.5} kDaA.baumanniïn mice erythrocytes

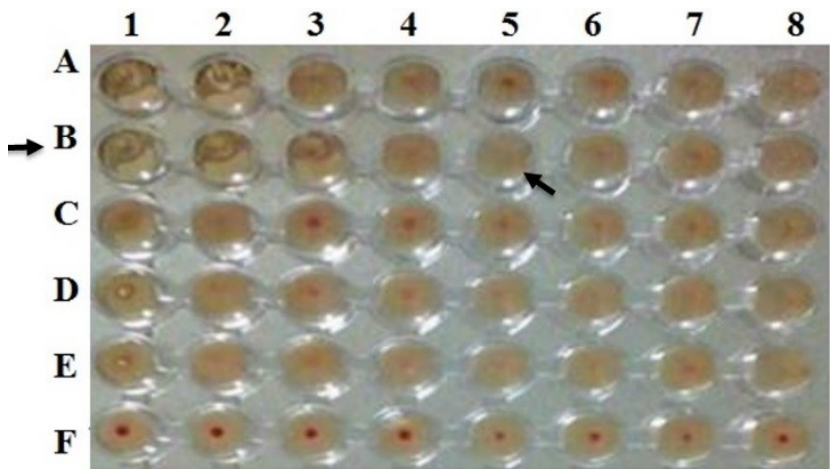

Figure 3. Result of hemagglutination test from OMP A.baumannii (13.5 kDa, 36.1 kDa, 45.2 kDa, 57.2 kDa and $76.5 \mathrm{kDa})$

\section{Description:}

A. Haemagglutination result of $76,5 \mathrm{kDa}$ OMP A.baumannii

B. Haemagglutination result of 57, 2kDa OMP A.baumannii

C. Haemagglutination result of 45, $2 \mathrm{kDa}$ OMP A.baumannii

D. Haemagglutination result of $36,1 \mathrm{kDa}$ OMP A.baumannii

E. Haemagglutination result of $13,5 \mathrm{kDa}$ OMP A.baumannii

F. PBS + erythrocytes (negative control)

$1-8$ : Dilution antigen (OMP) ${ }^{1 / 8,1 / 16,1 / 32,1 / 64,1 / 128,1 / 256,1 / 512,1 / 1.024}$ 
From the results of the hemagglutination test showed that the OMP with a molecular weight of 57.2 $\mathrm{kDa}$ showed the highest titer of $1 / 128$ and can be used as a protein hemagglutinin.

Characterization of $57.2 \mathrm{kDa}$ OMP antibody by dot blot method

Characterization of $57.2 \mathrm{kDa}$ OMP antibody performed by dot blotting method is shown below. The primary anti-OMP $57.2 \mathrm{kDa}$ were isolated from urine culture positive patients with secondary antibody antihuman IgA-AP conjugate with chromogen western blue, purplish blue which provide visualization of the presence of this molecule.

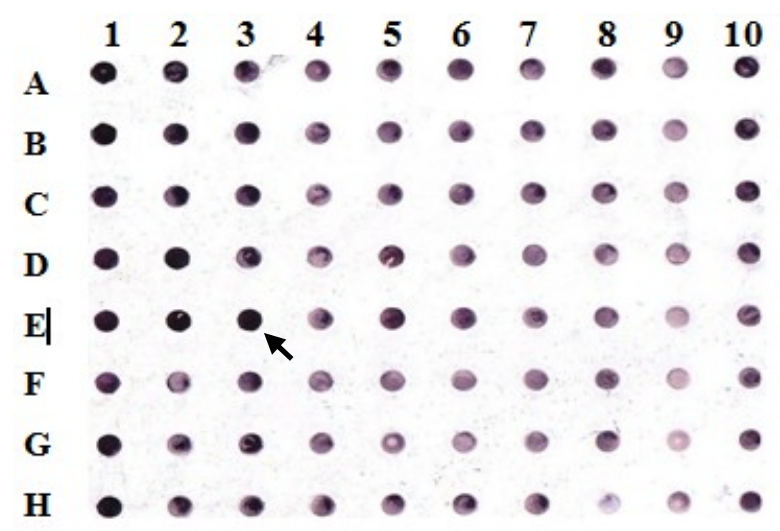

Figure 4. Result of the checker board antigen protein 57.2 kDa OMP A.baumanniiusing primary antibodies from urine of patients

\section{Description:}

1. Rows 1-8:dilution of antibody ${ }^{1 / 5,1 / 25,1 / 125,1 / 625,1 / 3.125,1 / 15.625,1 / 78.125,1 / 390.625}$

2. Columns A-H:dilution of antigen ${ }^{1 / 5,1 / 25,1 / 125,1 / 625,1 / 3.125,1 / 15.625,1 / 78.125,1 / 390.625}$

3. Best dilution E3 ( ${ }^{\mathbf{1 / 3 . 1 2 5}}$ antigen and for the antibody $\left.{ }^{1 / 125}\right)$

The dot blotting appears as purplish blue dot picture. The purplish blue dot that appears on the NC membrane showed 57.2 kDa OMP protein bound by anti-OMP antibody $57.2 \mathrm{kDa}$. The purplish blue dot indicates the $\mathrm{NC}$ membrane antigen-specific antibody response. The amount of antibody titers is determined by the value of the highest dilution that still has consistency of color dot thickness at or near the first dilution. The purplish blue color that is getting thinner in nitrocellulose membrane at the highest dilution (column E-3), indicates the smaller the antibody titer. The best dilution for antigen was $1 / 3.124$, and for the primary antibody was $1 / 125$.

\section{The immune response by Western blotting}

Characterization of $57.2 \mathrm{kDa}$ OMP antibody was conducted using Western blotting. The primary antibody anti- OMP $57.2 \mathrm{kDa}$ was isolated from the urine of patients with a positive culture results $\operatorname{sIgA}$ secondary antibody - AP conjugate anti- Human, the chromogen BCIP - NBT will provide visualization of the presence of the reddish brown protein . 57.2 kDa OMP.

The reddish brown color ribbon that appears on the membrane NC (Nitrocellulose) showed $57.2 \mathrm{kDa}$ OMP proteins transferred from SDS - PAGE gels bound by anti- OMP antibody $57.2 \mathrm{kDa}$. The reddish brown ribbon at the NC membrane indicates antigen - specific antibody responses at a molecular weight of $57.2 \mathrm{kDa}$ that is certain.

The production and isolation of polyclonal anti- OMP $57.2 \mathrm{kDa}$ A.baumanniiis characterized by the westernblottting method for the detection of humoral antibody response against specific antigens ( at BM 57.2 $\mathrm{kDa}$ ), the nitrocellulose membrane proteins that have been transferred from SDS-PAGE gel . The ribbon that appears on Western blotting in protein bound only by the polyclonal antibody anti- OMP 57.2 kDa. 
$\begin{array}{llllll}1 & 2 & 3 & 4 & 5 & 6\end{array}$

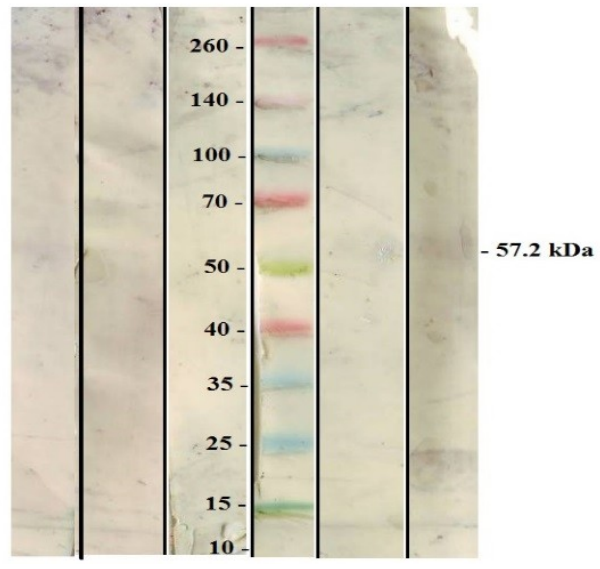

Figure 5. Result of OMP protein profile A.baumanniiusing the westernblotting with the primary antibody from the urine of patients

\section{Description:}

1. - A.baumannii

2. - A.baumannii

3. - A.baumannii

4. - Marker

5.+ A.baumannii

6.+ A.baumannii

From the picture the looks that are recognized by antibodies to OMP A.baumanniiis clearly A.baumanniiOMP with a molecular weight of $57.2 \mathrm{kDa}$. This is done by using the OMP 0.05 which is the same as the dominant protein bands that appear in the examination by SDS-PAGE

\section{Dot Blot}

A Dot blot test was done with the intent of testing whether the $57.2 \mathrm{kDa}$ OMP antigen A.baumanniibacteria was sensitive and specific for antibodies A.baumanniicontained in the urine of supernatant of patients. This test was performed on urine samples of 110 patients who had cultures taken and had been examined in the clinicallaboratory of microbiology, RSSA Malang. The urine will be examined later using a randomized Dot blot test. Used as antigen $57.2 \mathrm{kDa}$ OMP, the protein samples were secondary antibody which was anti- human IgA conjugate AP.

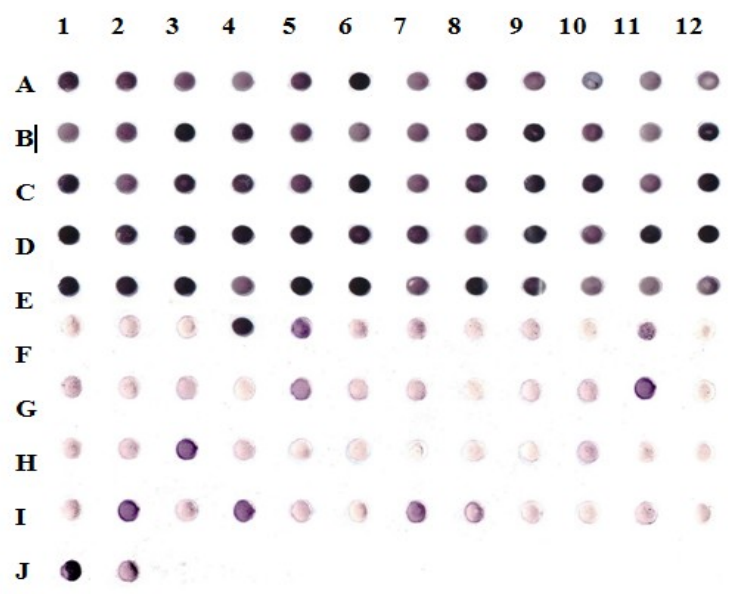

Figure 6. Results of dot blot antigen protein $57.2 \mathrm{kDa}$ OMP BM A.baumanniiusing primary antibodies from the urine of patients 
The dot blot results in the above picture shows the bond between the antigen and antibody suspected of being infected urine supernatant A.baumannii the $57.2 \mathrm{kDa}$ antigen. The quality of the dot colors shown indicates how high titers of antibodies to antigens are on Nitrocellulose paper.

From This result, the Dot data obtained were included in the program Corel Photo Pain 12, and by way of assessing each dot having different thicknesses, we will get the value of the quantitative difference. The thicker the color of the dot, the lower the mean value will be, which means also the more the resulting high antibody titers will be.

Table 1. Percentage sensitivity, specificity, positive predictive value and predictive value negative by changing the cut-off value of the mean to the table McNemar.

\begin{tabular}{|c|c|c|c|c|}
\hline Cut off mean & Sensitivity \% & Specificity \% & NPP \% & NPN \% \\
\hline 42,44 & 71,43 & 95,15 & 50,00 & 98,00 \\
\hline 75,61 & 71,43 & 71,84 & 14,71 & 97,37 \\
\hline 148,63 & 71,43 & 36,89 & 7,14 & 95,00 \\
\hline
\end{tabular}

Cut-off derived from the mean calculation using the program Corel Photo paint 12 $\mathrm{PPV}=$ positive prediction value, NPV $=$ Negative Prediction Value.

\section{Discussion}

An important early step in the colonization of the human urinary tract by bacteria is the adhesion of the organism to the host surface [19]. Bacterial adhesin proteins are generally grouped into two, fimbrialadhesin (FA) and afimbrialadhesin (AFA) [20]. In the afimbrialadhesin group including outermembraneprotein (OMP) [21], A.baumanniibacteria has two types of adhesin proteins that are in the form of pili and OMP [22]. Some research has been conducted relating to the pili proteins with a molecular weight of $38.8 \mathrm{kDa}$. Pili subunit hemaglutinin protein of A.baumanniiis an adhesin protein that can activate s-IgA production. While studied by Martino (2004) also had found that the OMP protein with a MW $25.8 \mathrm{kDaadhesin}$ molecules were able to inhibit the attachment of bacteria to the urinary bladder epithelial cells of rabbits. According to Salyers and Whitt (2002), afimbrialadhesin has a stronger attachment than the fimbrial adhesion. So it is expected that using the $25.8 \mathrm{kDa}$ OMP will increase the bond strength of the bacteria with host receptors. The current understanding of the mechanisms of attachment and characterization of adhesion molecules induce new thinking about the idea of adhesion moleculebased vaccine development. These vaccines have shown efficacy in the protection of infection.One example is the use of FimH from Escherichi coliadhesin for vaccines that can reduce bacterial colonization of the bladder mucosa of more than $99 \%$ in vivo in murine models of cystitis [23].

Outer Membrane Protein (OMP) is one of the layers of the cell wall, which is one part of the major antigens associated with nonspecific endo-toxin activity, especially in Gram-negative bacteria.

The first phase is an exploratory study aimed at the identification of OMP with a molecular weight protein. From the results of OMP electrophoresis A.baumannii, it showed that the OMP consists of several major and minor protein. High bands of protein were shown in OMP with concentrations $0.05 \%$ and $0.5 \%$ with molecular weight: $13.5 \mathrm{kDa}, 36.1 \mathrm{kDa}, 45.2 \mathrm{kDa}, 57.2 \mathrm{kDa}$ and $76.5 \mathrm{kDa}$. These corresponded with the calculations of the molecular weight.

In the next step of this study, proteins of $13.5 \mathrm{kDa}, 36.1 \mathrm{kDa}, 45.2 \mathrm{kDa}, 57.2 \mathrm{kDa}$ and $76.5 . \mathrm{kDa}$ OMP had been obtained and then performed the hemagglutination test of erythrocytes of mice to gain certainty whether these proteins can produce agglutination of red blood cells of mice. From the results, it is seen that the $57.2 \mathrm{kDa}$ OMP has the highest agglutination titer compared to the $13.5 \mathrm{kDa}, 36.1 \mathrm{kDa}, 45.2 \mathrm{kDa}$,and 76.5 . $\mathrm{kDa}$ OMP. Characterization of adhesion molecules can be known by the existence of the ability to agglutinate human red blood cells that have similar biological structure between the surfaces of red blood cells with epithelial cell receptors.

Keep in mind that the hemagglutinin protein adhesion molecule is identical to a cell surface receptor that is responsible for the interactions between cells and the extracellular matrix [24]. Data obtained in this study is that the $57.2 \mathrm{kDa}$ OMP protein is a protein that is identical to the protein hemagglutininadhesin.

Furthermore, OMP protein with a molecular weight of $57.2 \mathrm{kDa}$ obtained through the Western Blotting is test to observe whether these proteins can recognize A.baumannii antibodies against bacteria is thought to exist in the urine of patients. Western Blotting test was demonstrated on 5 urine samples. It is assumed that the Immunoglobulin A is contained in urine samples of patients A.baumannii. It is upheld by Baratawidjaya 2004 that immunoglobulin A is secreted by plasma cells contained in seromucous secretion such as saliva, tears, nasal cavity fluid, sweat, colostrum, the fluid secretion of the lungs, digestive tract and genirourinaria.

Test results show the Western blotting is a brownish red ribbon that ties $57.2 \mathrm{kDa}$ OMP protein antigen with a primary antibody s-IgA. These were tied again with the secondary antibody anti -human IgA on NC 
membrane. The bond shows proof that the $57.2 \mathrm{kDa}$ OMP protein is immunogenic proteins that produced antibody responses that provide specific anti- OMP $57.2 \mathrm{kDa}$ A.baumannii $[25,26]$.

Western blotting is usually used to determine the relative levels of a protein in a mixture of different types of proteins or other molecules. Western blotting methods combine selectivity with specificity immunoassay gel electrophoresis, so that each type of protein can be detected and analyzed by using the appropriate antibody probes. The proteins in the mixture were previously separated from one another by means of gel electrophoresis, SDS - PAGE in particular ways. The position at the end of each of the proteins in polyacrylamide gels after electrophoresis is terminated is in accordance with their respective molecular weights. The proteins that have been separated from one another were then transferred from the gel to a membrane support through capillary (blotting) such that the membranes get a replica of the composition of macromolecules as well as on the gel. The sought antigens can be identified on the membranes by treatment with specific antibodies marked or labeled with radioisotopes or enzymes. Various types of synthetic membranes can strongly bind to the protein so that it can be used as a medium of transport / membrane support for immunoassay on solid media. Proteins bound to membrane can easily maintain and react with antibodies [27].

The final stage of research is a diagnostic test to detect infection OMP A.baumannii through the Dot blot method. The Dot blot is a method developed in semi quantitative studies on immune tests to detect antigens. Samples containing antigens are dropped on the membrane labeled with antibodies. In this way, no such separation on SDS-PAGE is done. So Dot blot is only used to determine the type of antigen and not a protein of molecular weight. However, estimates of the concentration of the antigen can be detected in the blot, but is less accurate because it is difficult to accurately say the color arising on the blot. This method is good enough to use in a test or screening with enough samples [28]

Characterization of primary antibody immunogenicity in urine (s-IgA) by Dot blotting gives the result that the $57.2 \mathrm{kDa}$ OMP antigen is bound by anti- OMP -specific antibodies A.baumannii $57.2 \mathrm{kDa}$, which is characterized by a reddish brown dot on the NC membrane. The bonding evidence is that the $57.2 \mathrm{kDa}$ OMP protein is an immunogenic protein that responds to the specific antibody anti- OMP $57.2 \mathrm{kDa}$. Both of these methods can also be used to determine antibody titers which were marked with the thickness(density). Color dot immunogenic proteins are mainly protein having a molecular weight between $20000-100000 \mathrm{kDa}$ [29] When the molecular weight is less than $10,000 \mathrm{Da}$, it is usually not immunogenic [30]. Relative to the $57.2 \mathrm{kDa}$, OMP proteins in this study can be considered for use as an alternative carrier for human vaccination, especially mucosal vaccines. An important advantage of a mucosal vaccine development is the tendency to induce both mucosal and systemic responses. Because of the specific humoral defense given by the serum antibodies and antibody secretion mainly IgA, the improvement and development of future vaccines needed a method to induce both mucosal and systemic responses. The ability of such vaccines is currently the focus of vaccine development [31].

This study attempted to seek to quantify the results of dot blot method with the help of computer software using program Corel Photo paint 12. It is expected to perform quantification of data to assess the results of dot blot to get more accurate results about the results of these methods.

The results of the dot blot method are then measured for the thickness of the color by using the program Corel Photo - Paint 12. Data obtained from the program are in the form of the mean value, standard deviation, median and pixel. Subsequently, a table is created containing the relationships between the four parameters with each urine sample. Of the four parameters used, only one of the parameters is used to calculate the mean sensitivity and specificity of the method. From these results it appears that the lower the number, the thicker the mean dot is obtained with the mean figure being higher than the thin dot obtained. From the calculation of sensitivity and specificity of the dot blot method, McNemar table shows that the cut-off 42, 44 showed a sensitivity of $71,43 \%$ at a specificity of $95,15 \%$.Positive predictive $50,00 \%$ and negative predictive $98,00 \%$.

To select the best cut-off, it should be noted what the objective of the test diagnostics is. According to Pusponegoro (1995), when the diagnostic test intended for screening disease diagnostic test is needed, a high sensitivity is required but its specificity is not very high. This is possible when the diagnostic test intended for screening purposes is done after the diagnostic test for the next examination. But if the goal is to get rid of the disorder, it will require a diagnostic test with high specificity to avoid subjects that are not sick to do further diagnostic and therapeutic procedures that may be costly.

As a comparison, we should bear in mind the results of the sensitivity and specificity of the dot blot method in this study compared with similar studies that includes research conducted by Gill Means (1988) The Dot blot method for the detection of Chlamydia trachomatis infection specificity is compared with culture obtained of $97 \%, 81.5 \%$ NPP and NPN $99 \%$. Cabrera (1999). The Dot blot method is also applied for the detection of antibodies in patients with tuberculosis. In this study, the results of dot blot method has a sensitivity of $50 \%$ and specificity of $97.14 \%$. Besides, research conducted by Sugiri ( 2004 ) on the analysis of serum IgG, on tuberculosis patients with antigen $52 \mathrm{kDa}$ Mycobacterium tuberculosis using dot blot method, it showed a 
sensitivity of $33.33 \%$, specificity $56.18 \%$, positive predictive value and negative predictive value 32.7645 .08 $\%$. While research by Kurniawan (2005) on the sensitivity and specificity of the dot blot method using a 25.8 $\mathrm{kDa}$ OMP adhesion of Pseudomonas aeruginosa to detect urinary tract infections , obtained a sensitivity of 85.7 $\%$ and a specificity of $100 \%$.

The above results are in accordance with Sumarno, et al, (2004), who successfully used the protein immunogenic antigen $48 \mathrm{kDa}$ subunit of piliS.typhiIgG levels against examination typhoid fever patients by dot blotting method on blood samples of 123 patients get $94 \%$ sensitivity rate and specificity is $87 \%$ compared with the gold standard of culture.

This study has several drawbacks including the dot blot results using urine samples of patients with positive culture results with samples A.baumanniiurine culture not his A.baumannii. The dot blot results showed the same color, or nearly as dark a color. This makes Dot blot results difficult to assess in qualitative terms because everything gives results dot. The results of such an impact cannot be directly performed in the field and still need a computer to interpret the role.

Dot blot results of urine samples that still give the impression of a dot is expected to occur because of the possibility of crossing reaction in the presence of antibodies among bacteria as well as gram-negative rods with the possibility that patients with negative urine cultures in it also contained antibodies to the bacteria that may have plagued A.baumanniipatients. Other possibilities are:

- The number of bacteria in the urine is very little so that is not detected during examination under microscope.

- Urine culture may be negative but positive results may be caused by Dot blot bacteria A.baumanniiurine. As the urine is in small amounts, the seed might not have grown at that time as it is dominated by other bacteria or fungi that can kill bacteria A.baumannii.

\section{Conclusion}

\section{Conclusion And Suggestion}

Specific molecular weight proteins from bacterial OMP A.baumanniithat can respond to sIgA urine of patients is $57.2 \mathrm{kDa}$. Dot blot examination and based on the gold standard urine culture in 110 urine samples it showed that the $57.2 \mathrm{kDa}$ antigen humoral immune response capable to make reaction with s-IgA contained in urine for the diagnosis UTI at cut-off 42,44 , showed a sensitivity of $71,43 \%$ at a specificity of $95,15 \%$.Positive predictive $50,00 \%$ and negative predictive $98,00 \%$.

\section{Suggestion}

Hopefully the new innovations applied in this method and performed on bacteria in urine can be applied to bacteria in other diseases as well. It is hoped that the improvements in the working methods will be faster, more easily done and easily interpreted without the help of a computer device. Hopefully a method will be developed for the interpretation of Dot blot results without the help of computer devices with sensitivities and specificities yield equivalent to results interpreted by a computer. As expected in the foreseeable future, a method can be developed that can be applied directly in the field. Hopefully, further research can be done to improve the specificities of monoclonal antibody technology.

\section{References}

[1] Beyene, G and Tsegaye, W. 2011. Bacterial Uropathogensin Urinary Tract Infection and Antibiotic Susceptibility Pattern inJimma University Specialized Hospital, Southwest Ethiopia. Ethiop J Health Sci. 21(2): 141

[2] Alteri CJ, Hagan EC, Sivick KE, Smith SN, Mobley HLT.2009. Mucosal Immunization with Iron Receptor Antigens Protects against Urinary Tract Infection. PLoSPathog.5 (9): e1000586.

[3] Holt JG, Krieg NR, Sneath PHA, Staley JT, Williams ST. Bergey's Manual of Determinative of Bacteriology, 9th. Baltimor: William \& Wilkins; 1994.

[4] Seifert H, Dijkshoorn L, Gerner-Smidt P, Pelzer N, Tjernberg I and Vaneechoutte. Distribution of Acinetobacter species on Human skin: Comparison of Phenotypic and Genotypic Identification Methods. J ClinMicrobiol; 1997; 35: 2819-2825.

[5] Holmes B and Howard BJ. Nonfermentative Gram-Negative Bacteria. In: Clinical and Pathogenic Microbiology, 2nd ed. Howard BJ et al (ed.), St Louis, Washington DC, Toronto: CV Mosby Co; 1994: 337-364.

[6] Homenta H, Prawiro S R, Sardjono T W, Noorhamdani AS. 2014. The 38.8 kDaPili Subunit Hemaglutinin Protein of Acinetobacterbaumanniiis an Adhesin Protein that can activate s-IgA Production. IOSR Journal of Pharmacy and Biological Sciences (IOSR-JPBS). E-ISSN: 2278-3008, p-ISSN: 2319-7676. Volume 9, Issue 1 Ver. IV (Jan. 2014), PP 26-3

[7] Podschun R, ullmann U. Klebsiella spp. As Nosocomial Pathogens: Epidemiology, Taxonomy, Typing methods, and Pathogenicity Factors. Clinical microbiology Reviews 1998; 10:589-603.

[8] Kisra K. Relationships among Capsular Structure, Phagocytosis, and Mouse Virulence in Klebsiellapneumoniae. Infection and Immunity 1995;3: 847-52.

[9] Pillete C, Durham RS. Mucosal Immunity in Asthma and Chronic Obstructive Pulmonary Disease. Arole of Immunoglobulin A. Proc Am Thorac Sec 2004:1:125-35.

[10] Ehara, M., M. Ishibashi, M. and Ichinose, 1987. "Purification and partial characterization of fimbriae of Vibrio cholerae O1." Vaccine 5 (4): 283-8. 
[11] Sumarno R.P., Uun Y., Winarsih, Santoso S., Samsul I. 2012. Detection of molecule adhesion subunit pili 48 kDaSalmonellatyphiby immunochemistry method using sera patients suffering from typhoid fever. J. Basic. Appl. Sci. Res. 2: 8527-32.

[12] Manual of intruction in operating Scanning Electron Microscope FEI Inspect 550.

[13] Sumarno, R.P., Susanto, A., Ismanoe, G. and winarsih. 2011. Combinations of Protein Sub-Unit PILI 37.8 KDA V. Cholerae with Cholera Toxin Sub-Unit B V. Cholerae Can Protect Come Out of the Solution in the Intestinal Mice. J. Pharm. Biomed. Sci.

[14] Laemli, UK. 1970. Cleavage of structural protein during the assembly of the head of bacteriophage T4. Nature: 680-686

[15] Sumarno, R.P., Susanto, A., Ismanoe, G. andWinarsih S. 2011. Combinations of Protein Sub-Unit PILI 37.8 KDA V. Cholerae with Cholera Toxin Sub-Unit B V. Cholerae Can Protect Come Out of the Solution in the Intestinal Mice. J. Pharm. Biomed. Sci.

[16] Hanne, L.F and Finkelstein, R., A. 1982. Characterization and distribution of the hemagglutinins produced by Vibriocholerae. Infect Immun,.36(1): p. 209-14.

[17] Kyhse-Andersen, J. 1984. Electroblotting of multiple gels: a simple apparatus without buffer tank for rapid transfer of proteins from polyacrylamide to nitrocellulose. J BiochemBiophys Methods 10, 203-209.

[18] Protein Blotting Applications Guide, Technical Protocol TP001, 1997, Millipore Corporation, Bedford, Massachusetts, USA

[19] Torres A G, Zhou X and Kaper J B.2005. Adherence of Diarrhea genicEscherichia coli Strains to Epithelial Cells. Infect. Immun. 2005, 73(1):18. DOI: 10.1128/IAI.73.1.18-29.2005.

[20] GerlacR G, Hensel M.2007. Protein secretion systems and adhesins: The molecular armory of Gram-negative pathogens. International Journal of Medical Microbiology 297 (2007) 401-415.

[21] Patricia Renesto a, , Laurent Samson a, Hiroyuki Ogata b, SaïdAzza a, Patrick Fourquet c, Jean-Pierre Gorvel c, Robert A. Heinzen d, Didier Raoult. 2006. Identification of two putative rickettsialadhesins by proteomic analysis. Research in Microbiology 157 (2006) 605-612

[22] Breij, Anastasia de. Towards an explanation for the success of Acinetobacterbaumannii in the human host. The handle $\mathrm{http} / /$ hdl.handle.net/1887/19114 holds various files of this Leiden University dissertation. Issue Date: 2012-06-20.

[23] Langermann S, Palaszynski S, Barnhart M, Auguste G, Pinkner J.S, Burlein J, Barren P, Koenig S, Leath S, Jones C. H, Hultgren S. J.1997. Prevention of Mucosal Escherichia coli Infectionby FimH-Adhesin-Based Systemic Vaccination. Science .Vol. 276.

[24] Evan DG, Evan DJ, Moulds JJ, Graham DY. n-acetylnewraminyllactose-Binding FibrillarHemaglutinin of Compybacter Pylori: a Putative Colonization Factor Antigen. Infection and Immunity 1988; 56: 2896-960.

[25] Baldo, Tovey, St. Leonard. Protein Blotting Methodology, Research and Diagnostics Applications, KARGER, Switzerland. 1989.

[26] Wilson K, Walker J. Principles and Techniques of Practical Biochemistry. Cambridge University Press. 2000.

[27] Introduction to. Western Blotting. By Claire Moore, MSc. Principles. Technical Guidance. Data Analysis. Troubleshooting . 2012

[28] Abbas: Cellular and Molecular Immunology, 7th ed.Laboratory Techniques Commonly Used in Immunology : 513-514

[29] Harlow E, Lane D. Antibodies: A Laboratory Manual, Cold Spring Harbor Laboratory.1988.

[30] Parslow TG. Immunogens, Antigens and Vaccins.In: Stites DP, Terr Al, Parslow TG, Medical Immunology, 9th ed. ; USA: Applenton\& Lange;1998.p.74-82.

[31] Mc.GeeJR, Lam ME, Strober W. Mucosal Immune Responses: An Overvieew, in Ogra PL.et al. (Eds), manual Immunology ;USA; 2nd Academic Press:1999.p.485-506. 